\title{
La FEMECOT y las Universidades en la enseñanza de la Ortopedia
}

\author{
FEMECOT and Universities in the teaching of Orthopaedics
}

Gabriel Gerardo Huitrón Bravo*

*Expresidente de la Federación Mexicana de Ortopedia y Traumatología A.C.

La enseñanza de la medicina desde tiempos ancestrales se ha hecho de boca en boca y con el ejemplo, seguro los primeros humanos aprendieron a resolver sus problemas de salud por la observación y las pruebas de ensayo y error, enseñando a sus seguidores con el ejemplo. Los antiguos griegos - como Hipócrates y Aristóteles- enseñaban a sus discípulos hablando y caminando (como en el pase de visita actual en los hospitales). Fue hasta la invención del termómetro, el estetoscopio y los rayos $X$ que cambió el concepto de la medicina, ya que se afinaron los diagnósticos y con la anestesia y el uso de los antibióticos se mejoró el ejercicio profesional y, por supuesto, la transmisión del conocimiento.

En nuestro país fue hasta la década de los 40 que se crearon los grandes hospitales en la capital y con ellos se formalizó la enseñanza de las especialidades, el principal impulsor fue el Dr. Gustavo Baz Prada, que había sido rector de la UNAM, vinculando la enseñanza en los hospitales con la universidad y así se formaron los primeros especialistas con diploma universitario, éstos se fueron agrupando en sociedades y ahora en colegios. Estas agrupaciones rezan en su objeto la educación médica continua, misma que se hace entre pares a través de pláticas o conferencias mensuales programadas por oportunidad y que no corresponden a un programa con un objetivo definido, lo mismo se trata un tema que otro y no tienen un aval universitario, cumplen su función al otorgar puntos para mantener la certificación en el Consejo Mexicano de Ortopedia y Traumatología, pero sin un respaldo y calificación académica de la institución que vigiló nuestra formación, asimismo, nos apoya con la emisión de un diploma que avala nuestra formación; por tanto, se ha perdido el vínculo de nuestra agrupación con la institución educativa.

Aunque los integrantes de nuestros colegios cooperan con las más de 150 escuelas de medicina y las más de 70 sedes formadoras de ortopedistas, todos nos sujetamos a la normatividad académica, pero son acciones individuales, no hay un convenio de colaboración que relacione formalmente a una asociación o colegio con la alma mater.

De manera utópica esta relación debe existir en forma institucional, independientemente de quien las represente, nosotros retroalimentando los programas de las universidades y proponiendo no sólo los objetivos, sino al personal idóneo para estar frente al grupo o en los hospitales. Por otro lado, las instituciones deben apoyarse en las agrupaciones de expertos para fortalecer la enseñanza de los médicos de primer contacto y sobre todo en quienes recaerá la enseñanza del postgrado.

Juntos, universidades y nuestra FEMECOT, deben recorrer el camino de la Ortopedia Científica para beneficio del ser humano.
Correspondencia:

Gerardo Huitrón Bravo

E-mail: gghuitronb@uaemex.mx
Citar como: Huitrón BGG. La FEMECOT y las Universidades en la enseñanza de la Ortopedia. Orthotips. 2021; 17 (3): 130. https://dx.doi. org/10.35366/100620 